\title{
THERMAL RADIATION AND MASS TRANSFER EFFECTS ON MHD FREE CONVECTION FLOW PAST A VERTICAL CYLINDER WITH VARIABLE SURFACE TEMPERATURE AND CONCENTRATION
}

\author{
M. M. Gnaneswara Reddy ${ }^{1}$ and N. Bhaskar Reddy ${ }^{2}$ \\ ${ }^{1}$ Dept. of Mathematics, Sri Venkateswara University, Tirupati - 517502, Email: mgrsvu@gmail.com \\ 2 Dept. of Mathematics, Sri Venkateswara University, Tirupati - 517502
}

\begin{abstract}
:
The inte rac tion of fre e conv ection with the rm al radiation of a $v$ isc ous incom pressible un ste ady MHD flow $p$ as $t$ a $v$ ertical cylinde $r w$ ith $v$ ariable $s$ urfac e te mperature and concentration $i s$ a nalyzed. The flu id is a gray, ab sorbing-emitting bu $t$ non-scattering $m$ edium and the Rosseland ap proximation is use d to de scribe the radiative he atfl ux in the e ne rgy equa tion. The gov ern inge quations are solved usingan im plic it fin ite-diffe rence sche me of C rank-Nicols on ty pe. Num eric al re sults fo $r$ the tran sie $n t$ veloc ity, the te mperature, the concentration, the loc al as well a s average sk in-friction, the rate of he at and $m$ as stransfer a re show $n$ grap hic ally. It is obse rved that the presence of as $w$ ell as $i$ nc rease in the magne tic field le ads to de crease in the velocity field and $r$ ise in the the rm al bo undary thickness. The num erical pre dic ations hav e be en $c$ om pared $w$ ith the existing inform ation in the literature and good agr eement is o btained.
\end{abstract}

Keywords : Heat transfer, radiation, finite-difference Scheme, vertical cylinder.

\begin{tabular}{|c|c|}
\hline & 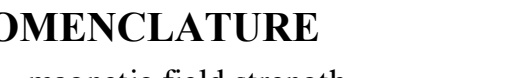 \\
\hline & rength \\
\hline & species concentration \\
\hline & ies concentrat \\
\hline$r$ & thermal Grashof number \\
\hline$i c$ & modified Grashof number \\
\hline & o gravity \\
\hline & grid point along the $X$ - direction \\
\hline & grid point along the $R$ - direction \\
\hline & $\begin{array}{l}\text { exponent in power law variation of } \\
\text { wall temperature }\end{array}$ \\
\hline & $\begin{array}{l}\text { exponent in power law variation of } \\
\text { wall concentration }\end{array}$ \\
\hline & magnetic parameter \\
\hline$N$ & radiation parameter \\
\hline & average Nusselt number \\
\hline$N u$ & local Nusselt number \\
\hline Dr & Prandtl number \\
\hline & radiative heat flux \\
\hline$R$ & $\begin{array}{l}\text { dimensionless radial co-ordinate } \\
\text { radical co-ordinate }\end{array}$ \\
\hline & radius of cylinder \\
\hline & Schmidt number \\
\hline & average Sherwood number \\
\hline
\end{tabular}

$S h_{X}$ local Sherwood number

$T$ temperature

$x \quad$ axial co-ordinate measured vertically upward direction

$t$ time

$X \quad$ dimensionless axial co-ordinate

$U, V$ dimensionless velocity components in $X, R$ directions respectively

Greek symbols

$\alpha$ thermal diffusivity

$\beta$ volumetric coefficient of thermal expansion

$\beta^{*}$ volumetric coefficient of expansion with concentration

$\Delta_{t}$ grid size in time

$\Delta_{R}$ grid size in radical direction

$\Delta_{X}$ grid size in axial direction

$k_{e}$ mean absorption coefficient

$v \quad$ kinematic viscosity

$\rho$ density

$\sigma$ Stefan-Boltzmann constant

$\tau_{x} \quad$ local skin-friction

$\bar{\tau}$ average skin-friction 


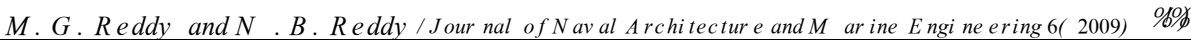

\section{Subscripts}

$w$ condition on the wall $\infty$ free-stream condition

\section{Introduction}

Unsteady natural convection flow of a viscous incompressible fluid over a heated vertical cylinder is an important problem relevant to many engineering applications. In the glass and polymer industries, hot filaments, which are considered as vertical cylinders, are cooled as they pass through the surrounding environment. For these types of non-linear problems, the exact solution is not possible. Sparrow and Gregg (1956) provided the first approximate solution for the laminar buoyant flow of air bathing a vertical cylinder heated with a prescribed surface temperature, by applying the similarity method and power series expansion. Lee et al. (1988) investigated the problem of natural convection in laminar boundary layer flow along slender vertical cylinders and needles for the power-law variation in wall temperature. Velusamy and Grag (1992) presented the numerical solution for transient natural convection over heat generating vertical cylinders of various thermal capacities and radii. The rate of propagation of the leading edge effect was given special consideration by them.

The effects of heat and mass transfer on the flow near vertical circular cylinder have been realized in many engineering and physical problems such as transport processes industry, ocean circulations due to heat current and difference in salinity etc. Combined buoyancy effects of thermal and mass diffusion along vertical cylinders have been given scant attention in the literature. Experimental results of pure and simultaneous heat and mass transfer by free convection along a vertical cylinder for $\mathrm{Pr}=0.71$ and $S c=0.63$ are given by Bottemanne (1972). Rani (2003) studied the transient natural convection along a vertical cylinder with variable temperature and mass diffusion, by employing an implicit finite-difference method of Crank-Nicolson type. Chen and Yuh (1980) considered the effects of heat and mass transfer on natural convective flow along a vertical cylinder, where the surface of the cylinder was either maintained at a uniform temperature/concentration or subjected to uniform heat/mass flux. They concluded that the combined buoyancy force from thermal and species diffusion provide larger Nusselt and Sherwood numbers for uniform surface heat/mass flux. Ganesan and Rani (1999) analyzed the unsteady free convection on vertical cylinder with variable heat and mass flux.

Magnetohydrodynamic (MHD) flow and heat and mass transfer processes occur in many industrial applications such as the geothermal system, aerodynamic processes, chemical catalytic reactors and processes, spreading of chemical pollutants in plants. Ganesan and Rani (2003) analyzed the magnetic field effect on a moving vertical cylinder with constant heat flux. Elbashbeshy (1997) studied heat and mass transfer along a vertical plate with variable surface temperature and concentration in the presence of magnetic field. Agarwal et al. (1989) considered the effect of MHD free convection and mass transfer flow past a vibrating infinite vertical circular cylinder. Combined heat and mass transfer effects on moving vertical cylinder that of steady and unsteady flow were investigated by Takhar et al. (2000), by using an implicit finite-difference scheme of Crank-Nicolson type. A numerical solution for the transient natural convection flow over a vertical cylinder under the combined buoyancy effect of heat and mass transfer was obtained by Ganesan and Rani (1998), by means of an implicit finite-difference scheme.

Heat transfer by simultaneous radiation and convection has applications in numerous technological problems, including combustion, glass production, furnace design, the design of high temperature gas cooled nuclear reactors, nuclear reactor safety, fluidized bed heat exchanger, fire spreads, advanced energy conversion devices such as open cycle coal and natural gas fired MHD, solar fans, solar collectors natural convection in cavities, turbid water bodies, photo chemical reactors and many others when heat transfer radiation is of the same order of magnitude as by convection, a separate calculation of radiation and their superposition without considering the interaction between them can lead to significant errors in the results, because of the presence of the radiation in the medium, which alters the temperature distribution within the fluid. Therefore, in such situation heat transfer by convection and radiation should be solved for simultaneously. In this context, Abd El-Naby et al. (2003) considered the effects of the radiation on unsteady free convective flow past a semi-infinite vertical plate with variable surface temperature using Crank-Nicolson finite difference method. RamachandrPrasad et al. (2006) analyzed the radiation effects on an unsteady two-dimensional hydromagnetic free convective boundary layer flow past a semi-infinite vertical plate with mass transfer in the presence of heat source/sink. The combined radiation and free convection flow over a vertical cylinder was presented by Yih (1999). Radiation 
and mass transfer effects on flow of an incompressible viscous fluid past a moving vertical cylinder was studied by Ganesan and Loganathan (2002).

However, the interaction of radiation and mass transfer in an electrically conducting fluid with variable surface temperature and concentration has received a little attention. Hence, the object of this paper is to study the radiation and mass transfer effects on MHD free convection flow of a viscous incompressible optically thick fluid past a vertical cylinder with variable surface temperature and concentration. The governing boundary layer equations along with the initial and boundary conditions are first cast into a dimensionless form and the resulting system of equations are then solved by an implicit finite-difference scheme. The behaviour of the velocity, temperature, concentration, skin-friction, Nusselt number and Sherwood number has been discussed for variations in the governing thermophysical and hydrodynamical parameters.

\section{Mathematical Analysis}

An unsteady two-dimensional laminar free convective heat and mass transfer flow of a viscous incompressible electrically conducting and radiating optically thick fluid past a semi-infinite vertical cylinder of radius $r_{0}$ is considered. The $x$-axis is taken along the axis of the cylinder and the radial coordinate $r$ is taken normal to the cylinder. Initially, the fluid and the cylinder are at the same temperature $T_{\infty}^{\prime}$ and the concentration $C_{\infty}^{\prime}$. At time ${ }_{t}{ }^{\prime}>0$, the temperature and concentration of the cylinder are raised to $T^{\prime}=T_{\infty}^{\prime}+\left(T_{w}^{\prime}-T_{\infty}^{\prime}\right)_{x}{ }^{m}, \quad C^{\prime}=C_{\infty}^{\prime}+\left(C_{w}^{\prime}-C_{\infty}^{\prime}\right)_{x}{ }^{n}$ respectively and are maintained constantly thereafter. A uniform magnetic field is applied in the direction perpendicular to the cylinder. The fluid is assumed to be slightly conducting, and hence the magnetic Reynolds number is much less than unity and the induced magnetic field is negligible in comparision with the applied magnetic field. It is further assumed that there is no applied voltage, so that electric field is absent. It is also assumed that the radiative heat flux in the $x$-direction is negligible as compared to that in the radial direction. The viscous dissipation is also assumed to be negligible in the energy equation due to slow motion of the cylinder. Also, it is assumed that there is no chemical reaction between the species and the fluid. The foreign mass present in the flow is assumed to be at low level and hence Soret and Dufour effects are negligible. It is also assumed that all the fluid properties are constant except that of the influence of the density variation with temperature and concentration in the body force term (Boussinesq's approximation). Then, under the above assumptions the governing boundary layer equations are

Continuity equation

$$
\frac{\partial(r u)}{\partial_{x}}+\frac{\partial\left({ }_{r v}\right)}{\partial_{r}}=0
$$

Momentum equation

$$
\frac{\partial_{u}}{\partial_{t}{ }^{\prime}}+{ }_{u} \frac{\partial_{u}}{\partial_{x}}+{ }_{v} \frac{\partial_{u}}{\partial_{r}}={ }_{g} \beta\left(T^{\prime}-{ }_{T_{\infty}^{\prime}}\right)+{ }_{g} \beta^{*}\left(C^{\prime}-{ }_{C}^{\prime}{ }_{\infty}\right)+\frac{v}{r} \frac{\partial}{\partial_{r}}\left(r \frac{\partial_{u}}{\partial_{r}}\right)-\frac{\sigma_{B 0}{ }^{2}}{\rho} u
$$

Energy equation

$$
\frac{\partial_{T}{ }^{\prime}}{\partial_{t}{ }^{\prime}}+{ }_{u} \frac{\partial_{T}{ }^{\prime}}{\partial_{x}}+{ }_{v} \frac{\partial_{T}{ }^{\prime}}{\partial_{r}}=\frac{\alpha}{r} \frac{\partial}{\partial_{r}}\left(r \frac{\partial_{T}{ }^{\prime}}{\partial_{r}}\right)-\frac{1}{\rho_{c_{p}}} \frac{1}{r} \frac{\partial}{\partial_{r}}\left({ }_{r q_{r}}\right)
$$

Mass diffusion equation

$$
\frac{\partial_{C}{ }^{\prime}}{\partial_{t}{ }^{\prime}}+{ }_{u} \frac{\partial_{C}{ }^{\prime}}{\partial_{x}}+{ }_{v} \frac{\partial_{C}{ }^{\prime}}{\partial_{r}}=\frac{D}{r} \frac{\partial}{\partial_{r}}\left(r \frac{\partial_{C}{ }^{\prime}}{\partial_{r}}\right)
$$

The initial and boundary conditions are

$$
t^{\prime} \leq 0:{ }_{u}=0, \quad v=0, \quad T^{\prime}=T_{\infty}^{\prime}, \quad C^{\prime}=C_{\infty}^{\prime} \quad \text { for all } x \geq 0 \text { and } r \geq 0
$$




$$
\begin{aligned}
t^{\prime}>0: & u=0, \quad v=0, \quad T^{\prime}=T_{\infty}^{\prime}+\left(T_{w}^{\prime}-T_{\infty}^{\prime}\right)_{x}{ }^{m}, C^{\prime}=C_{\infty}^{\prime}+\left(C_{w}^{\prime}-C_{\infty}^{\prime}\right)_{x}{ }^{n} \text { at } r={ }_{r 0} \\
u & =0, \quad T^{\prime}=T_{\infty}^{\prime}, C^{\prime}=C_{\infty}^{\prime} \quad \text { at } \quad x=0 \text { and } r{ }_{r 0} \\
u & \rightarrow 0, T^{\prime} \rightarrow T_{\infty}^{\prime}, C^{\prime} \rightarrow C_{\infty}^{\prime} \quad \text { as } \quad r \rightarrow \infty
\end{aligned}
$$

By using the Rosseland approximation (Brewster (1992)), the radiative heat flux $q_{r}$ is given by

$$
q_{r}=-\frac{4 \sigma_{s}}{3_{k_{e}}} \frac{\partial_{T}{ }^{\prime 4}}{\partial_{r}}
$$

where $\sigma_{s}$ is the Stefan-Boltzmann constant and $k_{e}$ - the mean absorption coefficient. It should be noted that by using the Rosseland approximation, the present analysis is limited to optically thick fluids. If the temperature differences within the flow are sufficiently small, then Equation (6) can be linearized by expanding $T^{\prime 4}$ into the Taylor series about $T_{\infty}^{\prime}$, which after neglecting higher order terms takes the form

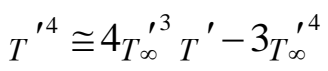

In view of Equations (6) and (7), Equation (3) reduces to

$$
\frac{\partial_{T}{ }^{\prime}}{\partial_{t}{ }^{\prime}}+{ }_{u} \frac{\partial_{T}{ }^{\prime}}{\partial_{x}}+{ }_{v} \frac{\partial_{T}{ }^{\prime}}{\partial_{r}}=\frac{\alpha}{r} \frac{\partial}{\partial_{r}}\left(r \frac{\partial_{T}{ }^{\prime}}{\partial_{r}}\right)+\frac{16 \sigma_{s} T_{\infty}^{\prime 3}}{3_{k_{e}} \rho_{c_{p}}} \frac{1}{r} \frac{\partial}{\partial_{r}}\left(r \frac{\partial_{T}{ }^{\prime}}{\partial_{r}}\right)
$$

In order to write the governing equations and the boundary conditions in dimensionless form, the following nondimensional quantities are introduced.

$$
\begin{aligned}
& X=\frac{x}{r_{0}}, \quad R=\frac{r}{r_{0}}, \quad U=\frac{u r 0}{v}, V=\frac{v r_{0}}{v}, \quad t=\frac{v_{t}^{\prime}}{{ }^{2}}, \quad T=\frac{T^{\prime}-T_{\infty}^{\prime}}{T_{w}^{\prime}-T_{\infty}^{\prime}}, \\
& M=\frac{\sigma_{B 0 r 0}^{2}{ }^{2}}{v}, C=\frac{C^{\prime}-C_{\infty}^{\prime}}{C_{w}^{\prime}-C_{\infty}^{\prime}}, G r=\frac{g \beta_{r 0}^{3}\left(T_{w}^{\prime}-T_{\infty}^{\prime}\right)}{v^{2}}, G c=\frac{g \beta_{r 0}^{*}\left(C_{w}^{\prime}-C_{\infty}^{\prime}\right)}{v^{2}}, \\
& S c=\frac{v}{D}, \quad N=\frac{k^{*} k}{4 \sigma_{T}^{\prime \prime}}
\end{aligned}
$$

In view of the Equation (9), the Equations (1), (2), (8) and (4) reduce to the following non-dimensional form

$$
\begin{aligned}
& \frac{\partial\left(_{R U}\right)}{\partial_{X}}+\frac{\partial(R V)}{\partial_{R}}=0 \\
& \frac{\partial_{U}}{\partial_{t}}+{ }_{U} \frac{\partial_{U}}{\partial_{X}}+{ }_{V} \frac{\partial_{U}}{\partial_{R}}=G r T+{ }_{G c} C+\frac{1}{R} \frac{\partial}{\partial_{R}}\left(R \frac{\partial_{U}}{\partial_{R}}\right)-{ }_{M U} \\
& \frac{\partial_{T}}{\partial_{t}}+_{U} \frac{\partial_{T}}{\partial_{X}}+{ }_{V} \frac{\partial_{T}}{\partial_{R}}=\frac{1}{\operatorname{Pr}}\left(1+\frac{4}{3_{N}}\right) \frac{1}{R} \frac{\partial}{\partial_{R}}\left(R \frac{\partial_{T}}{\partial_{R}}\right) \\
& \frac{\partial_{C}}{\partial_{t}}+{ }_{U} \frac{\partial_{C}}{\partial_{X}}+_{V} \frac{\partial_{C}}{\partial_{R}}=\frac{1}{S_{C}} \frac{1}{\partial_{R}}\left(R \frac{\partial_{C}}{\partial_{R}}\right)
\end{aligned}
$$

The corresponding initial and boundary conditions are 
${ }_{t} \leq 0:{ }_{U}=0, V=0, T=0, C=0 \quad$ for all $X \geq 0$ and ${ }_{R} \geq 0$

$$
\begin{array}{rlrl}
{ }_{t}>0:_{U} & =0, V=0, T=X^{m},{ }_{C}=X^{n} \quad \text { at } \quad R=1 \\
U & =0, T=0, C=0 & \text { at } X=0 \text { and }{ }_{R} \geq 1 \\
U & \rightarrow 0,{ }_{T} \rightarrow 0, C \rightarrow 0 \quad \text { as } \quad R \rightarrow \infty
\end{array}
$$

Knowing the velocity, temperature and concentration fields, it is interesting to find the skin-friction, Nusselt number and Sherwood numbers are defined as follows.

Local and average skin-frictions in non-dimensional form are

$$
\begin{aligned}
& \tau_{X}=-\left(\frac{\partial_{U}}{\partial_{R}}\right)_{R=1} \\
& \bar{\tau}=-\int_{0}^{1}\left(\frac{\partial_{U}}{\partial_{R}}\right)_{R=1} d X
\end{aligned}
$$

Local and average Nusselt numbers in non-dimensional form are

$$
\begin{aligned}
& N u_{X}=-X\left[\frac{\left(\frac{\partial_{T}}{\partial_{R}}\right)}{T_{R}=1}\right] \\
& \overline{N u}=-\int_{0}^{1}\left[\frac{\left(\frac{\partial_{T}}{\partial_{R}}\right)_{R=1}}{T_{R}=1}\right] d X
\end{aligned}
$$

Local and average Sherwood numbers in non-dimensional form are

$$
\begin{aligned}
& S h_{X}=-X\left[\frac{\left(\frac{\partial_{C}}{\partial_{R}}\right)_{R=1}}{C_{R}=1}\right] \\
& \overline{S h}=-\int_{0}^{1}\left[\frac{\left(\frac{\partial_{C}}{\partial_{R}}\right)_{R}=1}{C_{R}=1}\right] d X
\end{aligned}
$$

\section{Numerical Technique}

In order to solve the unsteady, non-linear, coupled Equations (10) - (13) under the conditions (14), an implicit finite difference scheme of Crank-Nicolson type has been employed. 
The finite difference equations corresponding to Equations (10) - (13) are as follows:

$$
\begin{aligned}
& \frac{\left[U_{i, j}^{n+1}-U_{i-1, j}^{n+1}+U_{i, j}^{n}-U_{i-1, j}^{n}+U_{i, j-1}^{n+1}-U_{i-1, j-1}^{n+1}+U_{i, j-1}^{n}-U_{i-1, j-1}^{n}\right]}{4 \Delta X}+\frac{\left[V_{i, j}^{n+1}-V_{i, j-1}^{n+1}+V_{i, j}^{n}-V_{i, j-1}^{n}\right]}{2 \Delta R} \\
& +\frac{V_{i, j}^{{ }^{+1}}}{1+\left({ }_{j}-1\right) \Delta_{R}}=0
\end{aligned}
$$

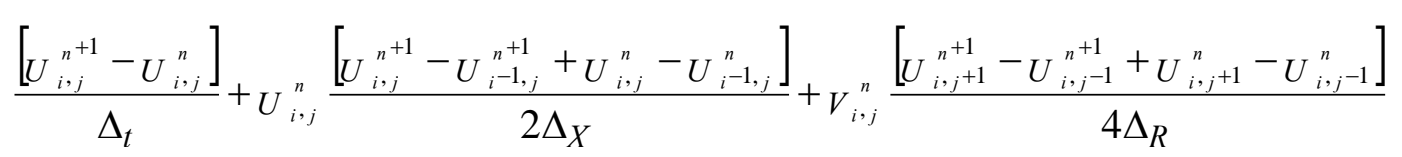

$$
\begin{aligned}
& =G r \frac{\left[T_{i, j}^{n^{+1}}+T_{i, j}^{n}\right]}{2}+G m \frac{\left[C_{i, j}^{n^{+1}}+C_{i, j}^{n}\right]}{2}+\frac{\left[U_{i, j}^{n^{+1}-1}-2 U_{i, j}^{n^{+1}}+U_{i, j}^{n^{+1}+1}+U_{i, j}^{n^{+1}}-2_{U_{i, j}^{n}}^{n}+U_{i, j+1}^{n}\right]}{2\left(\Delta_{R}\right)^{2}} \\
& +\frac{\left[U_{i, j+1}^{n+1}-U_{i, j-1}^{n+1}+U_{i, j+1}^{n}-U_{i, j-1}^{n}\right]}{4\left[1+(j-1) \Delta_{R}\right] \Delta_{R}}-\frac{M}{2}\left[U_{i, j}^{n^{+1}}+U_{i, j}^{n}\right]
\end{aligned}
$$

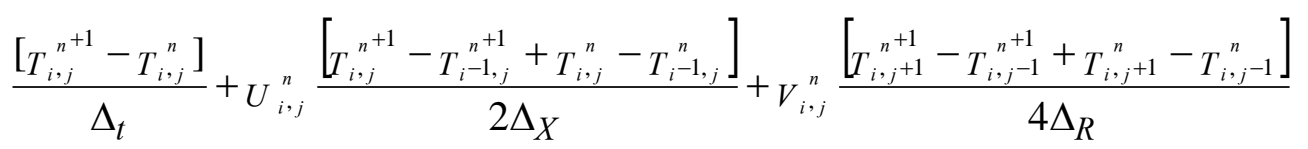

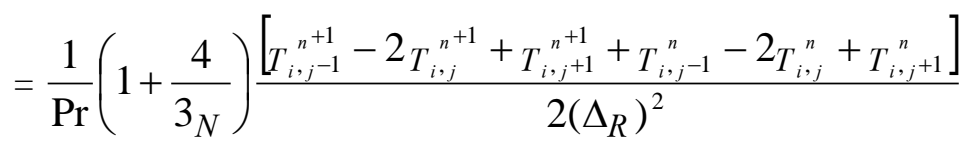

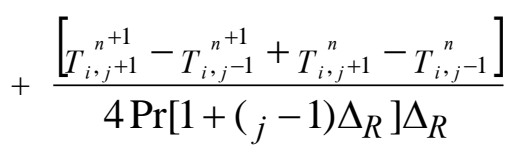

$$
\begin{aligned}
& \frac{\left[C_{i, j}^{n^{n+1}}-C_{i, j}^{n}\right]}{\Delta_{t}}+U_{i, j}^{n} \frac{\left[C_{i, j}^{n^{n+1}}-C_{i-1, j}^{n^{+1}}+C_{i, j}^{n}-C_{i^{-1, j},}^{n}\right]}{2 \Delta_{X}}+V_{i, j}^{n} \frac{\left[C_{i, j}^{n^{n+1}}-C_{i, j}^{n^{+1}-1}+C_{i, j}^{n}-C_{i, j}^{n}\right]}{4 \Delta_{R}}
\end{aligned}
$$

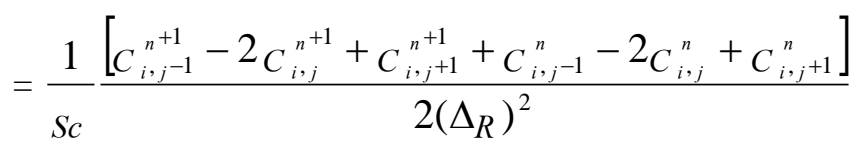

$$
\begin{aligned}
& +\frac{\left[C_{i, j}^{n+1}-C_{i, j-1}^{n+1}+C_{i, j+1}^{n}-C_{i, j-1}^{n}\right]}{4_{S c}\left[1+\left({ }_{j}-1\right) \Delta_{R}\right] \Delta_{R}}
\end{aligned}
$$

The region of integration is considered as a rectangle with sides $X$ max $(=1)$ and $R_{\max }(=14)$, where $R$ max corresponds to $_{R}=\infty$, which lies very well outside the momentum, energy and concentration boundary Thermal radiation and mass transfer effects on MHD free convection flow.... 
layers. The maximum of $R$ was chosen as 14 after some preliminary investigations, so that the last two of the boundary conditions (14) are satisfied. Here, the subscript $i$ - designates the grid point along the X - direction, $j$ - along the $R_{R}$ - direction and the superscript ${ }_{n}$ along the ${ }_{t}$ - direction. The appropriate mesh sizes considered for the calculation are $\Delta_{X}=0.05, \Delta_{R}=0.25$, and time step $\Delta_{t}=0.01$. During any one-time step, the coefficients $U_{i, j}^{n}$ and $V_{i, j}^{n}$ appearing in the difference equations are treated as constants. The values of $U, V, T$ and $C_{C}$ are known at all grid points at $t_{t}=0$ from the initial conditions. The computations of $U, V, T$ and $C_{C}$ at time level $\left({ }_{n+1}\right)$ using the known values at previous time level $(n)$ are calculated as follows.

The finite difference Equation (24) at every internal nodal point on a particular ${ }_{i}$ - level constitute a tri-diagonal system of equations. Such a system of equations is solved by Thomas algorithm as described in Carnahan et al. (1969). Thus, the values of $C_{C}$ are found at every nodal point on a particular $i$ at $\left({ }_{n+1}\right)^{\text {th }}$ time level. Similarly, the values of $T_{T}$ are calculated from the Equation (23). Using the values of $C_{C}$ and $\mathrm{T}$ at $\left({ }_{n+1}\right)^{\text {th }}$ time level in the Equation (22), the values of $U$ at $(n+1)^{\text {th }}$ time level are found in a similar manner. Thus the values of $C, T$ and ${ }_{U}$ are known on a particular ${ }_{i}$ - level. The values of $V$ are calculated explicitly using the Equation (21) at every nodal point on a particular $i_{i}$ - level at $\left({ }_{n+1}\right)^{\text {th }}$ time level. This process is repeated for various $i^{-}$ levels. Thus, the values of $C, T, U$ and $V$ are known at all grid points in the rectangular region at $\left({ }_{n+1}\right)^{\text {th }}$ time level. Computations are carried out till the steady state is reached. The steady state solution is assumed to have been reached, when the absolute difference between the values of ${ }_{U}$ as well as temperature ${ }_{T}$ and concentration $C$ at two consecutive time steps are less than $10^{-5}$ at all grid points.

After experimenting with few sets of mesh sizes, they have been fixed at the level $\Delta_{X}=0.05, \Delta_{R}=0.25$, and the time step $\Delta_{t}=0.01$.In this case, spatial mesh sizes are reduced by $50 \%$ in one direction, and then in both directions, and the results are compared .It is observed that, when the mesh size is reduced by $50 \%$ in $X$ direction and $R_{R}$ - direction, the results differ in the fourth decimal places. The computer takes more time to compute, if the size of the time-step is small. Hence, the above mentioned sizes have been considered as appropriate mesh sizes for calculation.

The local truncation error in the finite-difference approximation is $O\left(\Delta_{t}{ }^{2}+\Delta_{R}{ }^{2}+\Delta_{X}\right)$ and it tends to zero as $\Delta_{X}, \Delta_{R}$ and $\Delta_{t}$ tend to zero. Hence the scheme is compatible. Stability and compatibility ensures convergence (Richtmyer and Morton (1967)).

The derivatives involved in the Equations (15) - (20) are evaluated using five-point approximation formula and the integrals are evaluated using Newton-Cotes closed integration formula.

\section{Results and Discussion}

In order to get a physical insight into the problem, a representative set of numerical results is shown graphically in Figs. 1-12, to illustrate the influence of governing parameters viz., radiation parameter $N$, thermal Grashof number $_{G r}$, solutal Grashof number $G c$, magnetic parameter $M$, Prandtl number Pr, Schmidt number $S c$, exponent in the power law variation of the wall temperature ${ }_{m}$, exponent in the power law variation of the wall concentration ${ }_{n}$ on the velocity, temperature and concentration, skin-friction, Nusselt number and Sherwood number. Here the value of $\operatorname{Pr}$ is chosen as 0.71 , which corresponds a air. The values of $S c$ are chosen such that they represent water vapour (0.6) and Ammonia (0.78).

In order to ascertain the accuracy of the numerical results, the present study is compared with the previous study. The velocity profiles for $G_{c}=2.0,{ }_{N}=0.0,{ }_{M}=0.0, \operatorname{Pr}=0.7,{ }_{X}=1.0, S c=0.6$ are compared with the 
available solution of Rani [5], in Fig.1. It is observed that the present results are in good agreement with that of Rani [5].

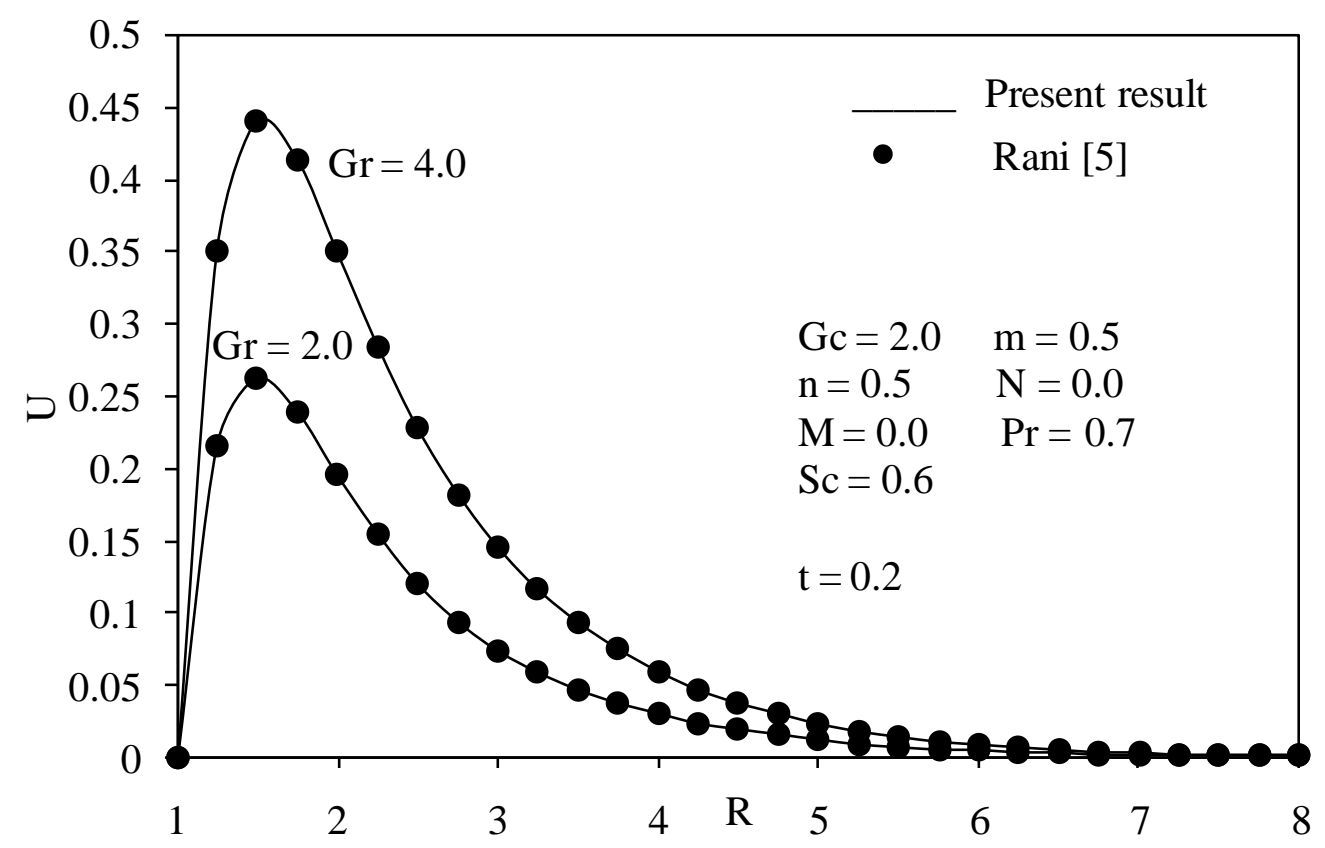

Fig.1. Comparison of velocity profiles

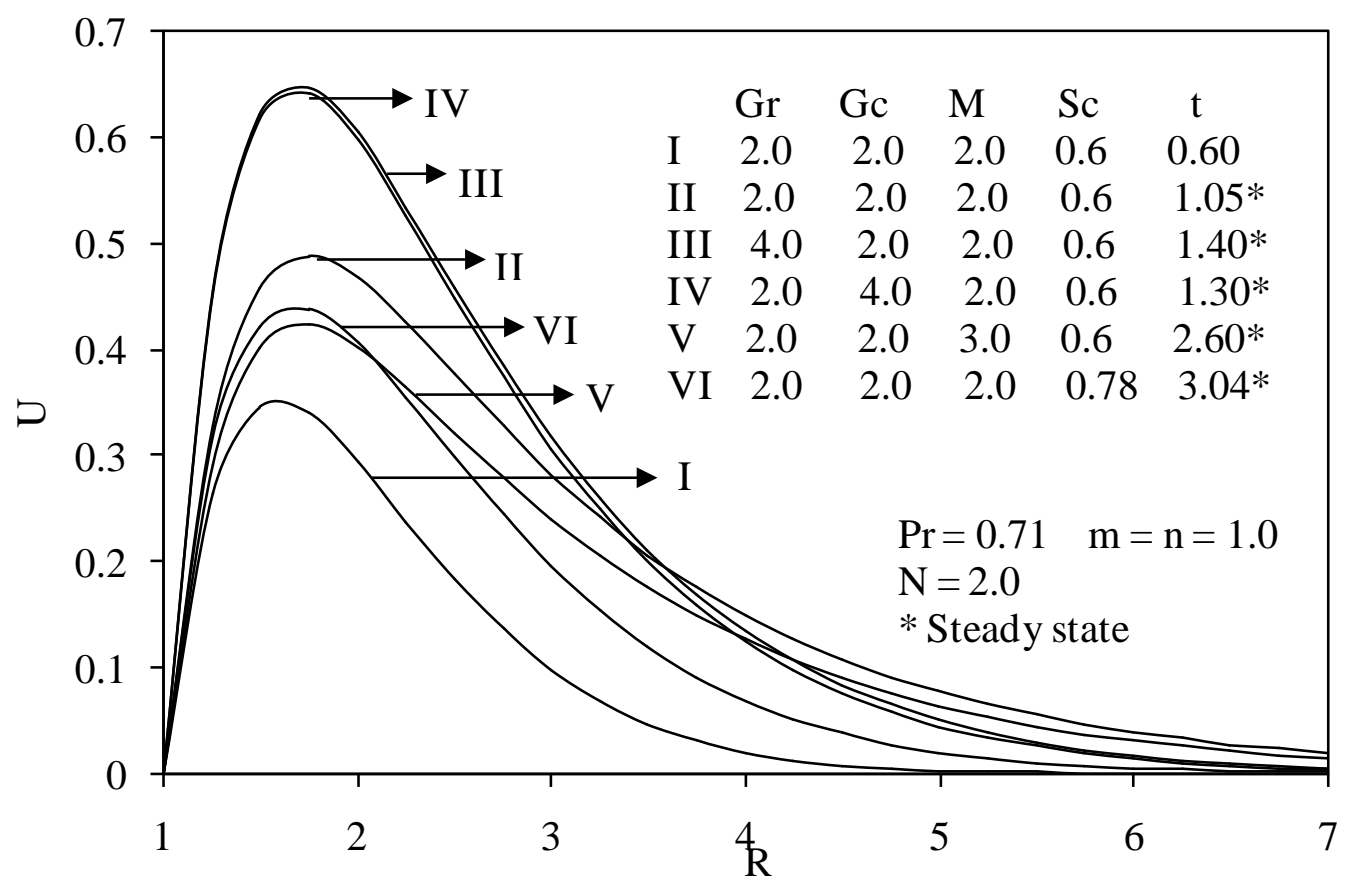

Fig.2. Transient velocity profiles at $\mathrm{X}=1.0$ for different $\mathrm{Gr}, \mathrm{Gc}, \mathrm{M}$ and Sc

The transient and steady state velocity profiles at $\mathrm{X}=1.0$ for different values $G r, G c, M$ and $S c$ are shown in Fig. 2. The thermal Grashof number signifies the relative effect of the thermal buoyancy (due to density differences) force to the viscous hydrodynamic force in the boundary layer flow. Here the positive values of $G r$ correspond to cooling of the cylinder. As expected, it is noticed that an increase in ${ }_{G r}$ leads to a rise in the 
values of velocity due to enhancement in the buoyancy force. The solutal Grashof number ${ }_{G c}$ defines the ratio of the species buoyancy force to the viscous hydrodynamic force. It is found that the fluid velocity increases and the peak value becomes more distinctive due to an increase in the concentration buoyancy force represented by $G c$ (Fig. 2.) Also, the momentum boundary layer thickness increases with increasing values of $G r$ or $G c$. The contribution of mass diffusion to the buoyancy force increases the maximum velocity significantly. The time required to reach the steady state velocity increases as $G r$ or $G c$ increases. It is observed that an increase in the magnetic field parameter leads to a decrease in the velocity field. It is because that the application of transverse magnetic field will result in a resistive type force (Lorentz force) similar to drag force which tends to resist the fluid flow and thus reducing its velocity. Also, the boundary layer thickness decreases with an increase in the magnetic parameter. The Schmidt number $S_{c}$ signifies the ratio of the momentum diffusivity to the mass (species) diffusivity. It physically relates the relative thickness of the hydrodynamic boundary layer and masstransfer (concentration) boundary layer. It is noticed that as the Schmidt number increases the velocity decreases. It is observed that the time required to reach the steady state velocity increases with an increase in $M$ or $S c$.

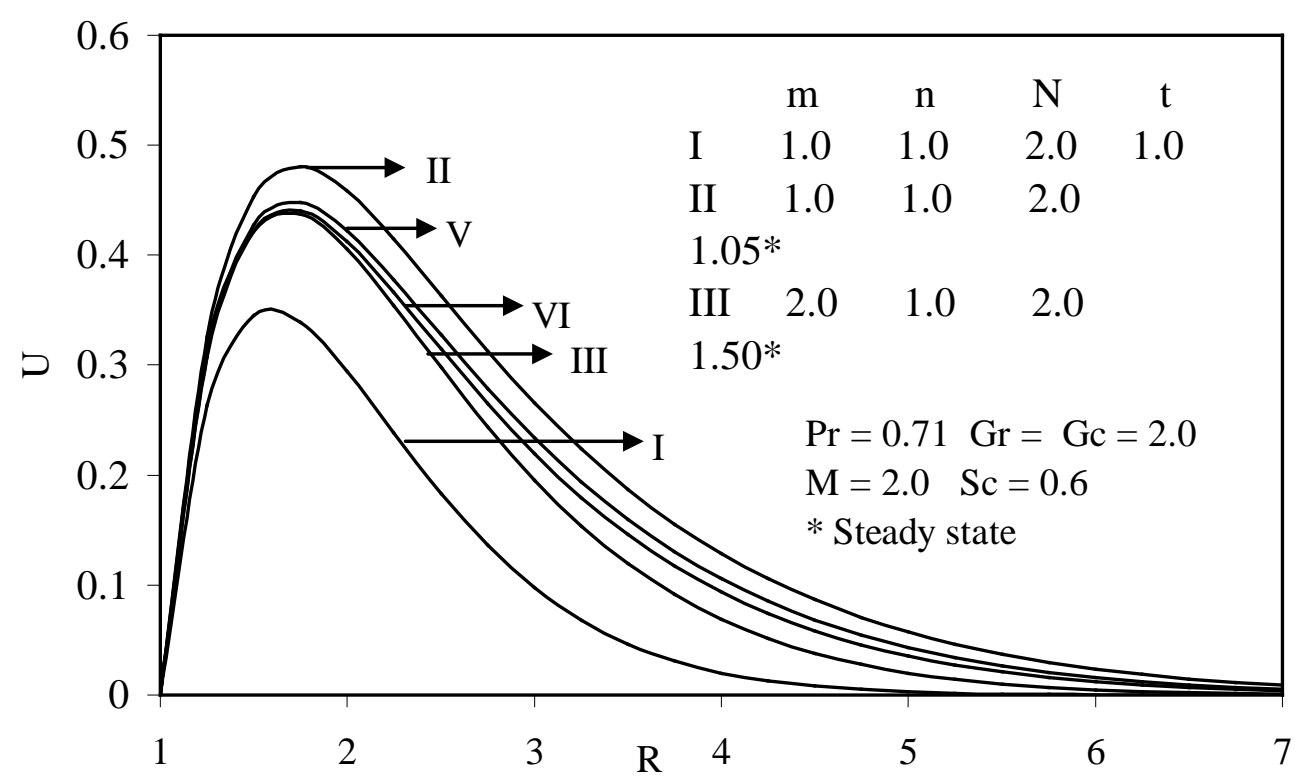

Fig.3. Transient velocity profiles at $\mathrm{X}=1.0$ for different $\mathrm{m}, \mathrm{n}$ and $\mathrm{N}$

Fig. 3 depicts the transient and steady state velocity profiles for different values of radiation parameter ${ }_{N}, \mathrm{~m}$ and $n$. The radiation parameter ${ }_{N}$ (i.e., Stark number) defines the relative contribution of conduction heat transfer to thermal radiation transfer. It can be found that an increase in $N$ leads to a decrease in the velocity within the boundary layer as well as decreased thickness of the hydrodynamic boundary layer. It is also noticed that the velocity decreases with an increase in $m$ or $n$. The time required to reach the steady state velocity increases as $N$ or $m$ or $n$ increases.

The transient and steady-state temperature profiles at $\mathrm{X}=1.0$ for different values of $m, n$ and $N$ are shown in Fig.4. It is found that as ${ }_{N}$ increases from 2.0 to 5.0, the temperature decreases markedly throughout the length of the cylinder. As a result the thermal boundary layer thickness decreases due to a rise in ${ }_{N}$ values. Also, it is noticed that the temperature decreases as $m$ or $n$ increases. The effect of ${ }_{m}$ is more important on temperature than $_{n}$. It is also seen that the time taken to reach the steady state temperature increases with an increase in $m$ or $_{n}$ or $_{N}$.

The concentration profiles for different values of $m$ and $n$ are shown in Fig.5. It is found that the concentration decreases with an increase in $m$ or $n$. Here, the effect of $n$ is more important than the effect of $m$. The time required to reach the steady state concentration increases with an increase in $m$ or $n$. The 
transient and steady-state concentration profiles at $\mathrm{X}=1.0$ for different values of ${ }_{N}$ and $S c$ are shown in Fig.6.

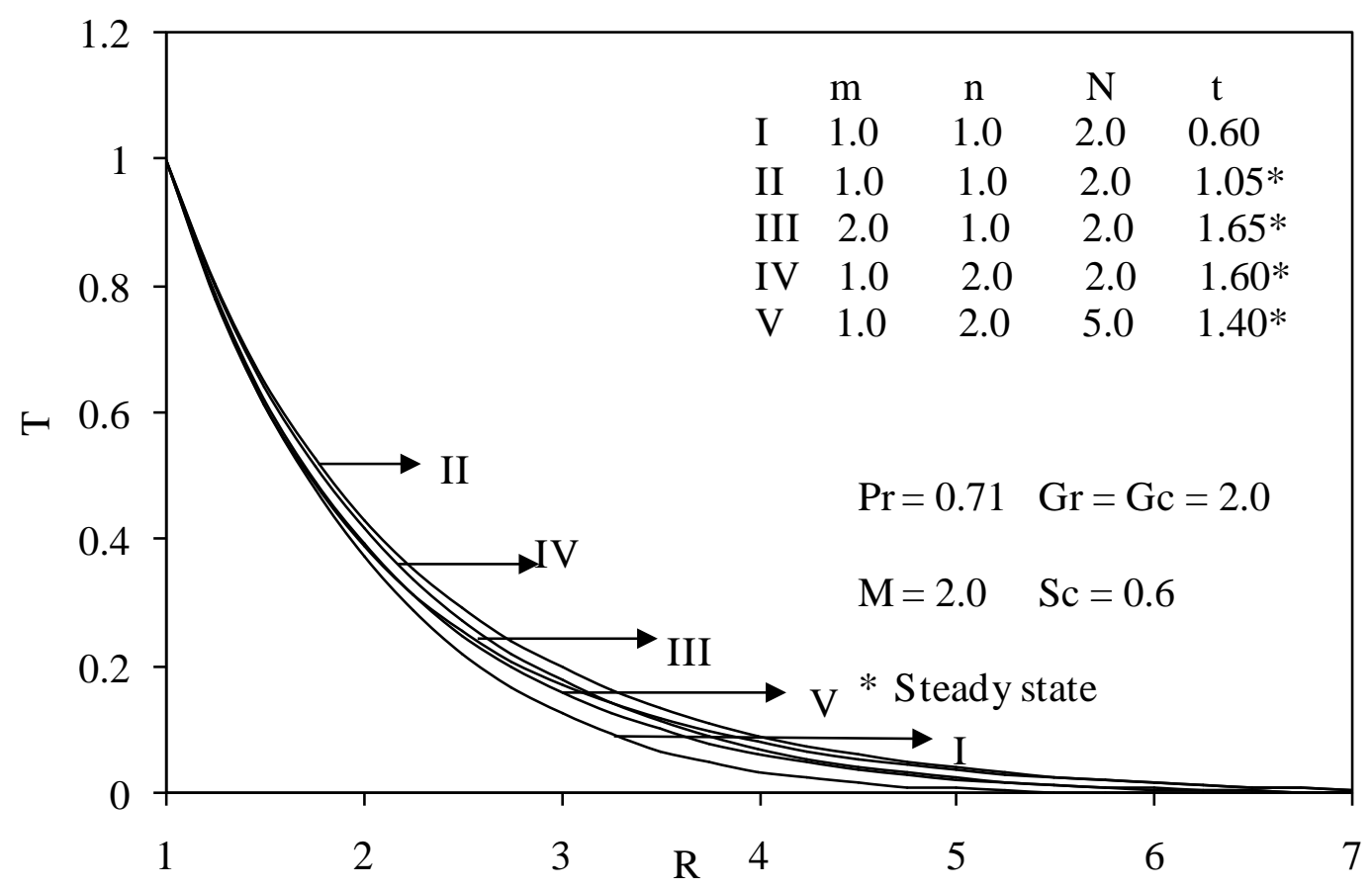

Fig.4. Transient temperature profiles at $\mathrm{X}=1.0$ for different $\mathrm{m}, \mathrm{n}$ and $\mathrm{N}$

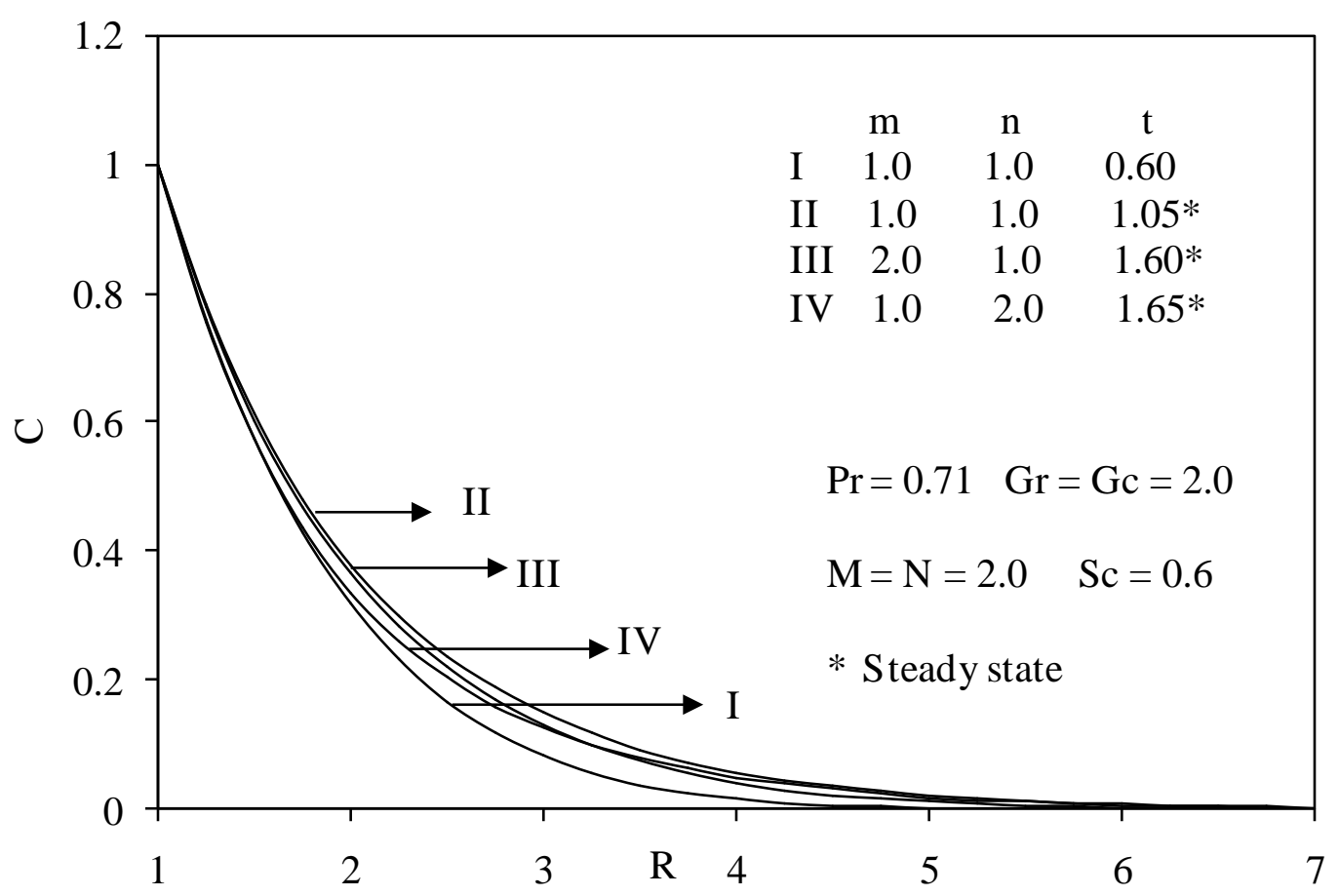

Fig.5. Transient concentration profiles at $X=1.0$ for different $m$ and $n$ 


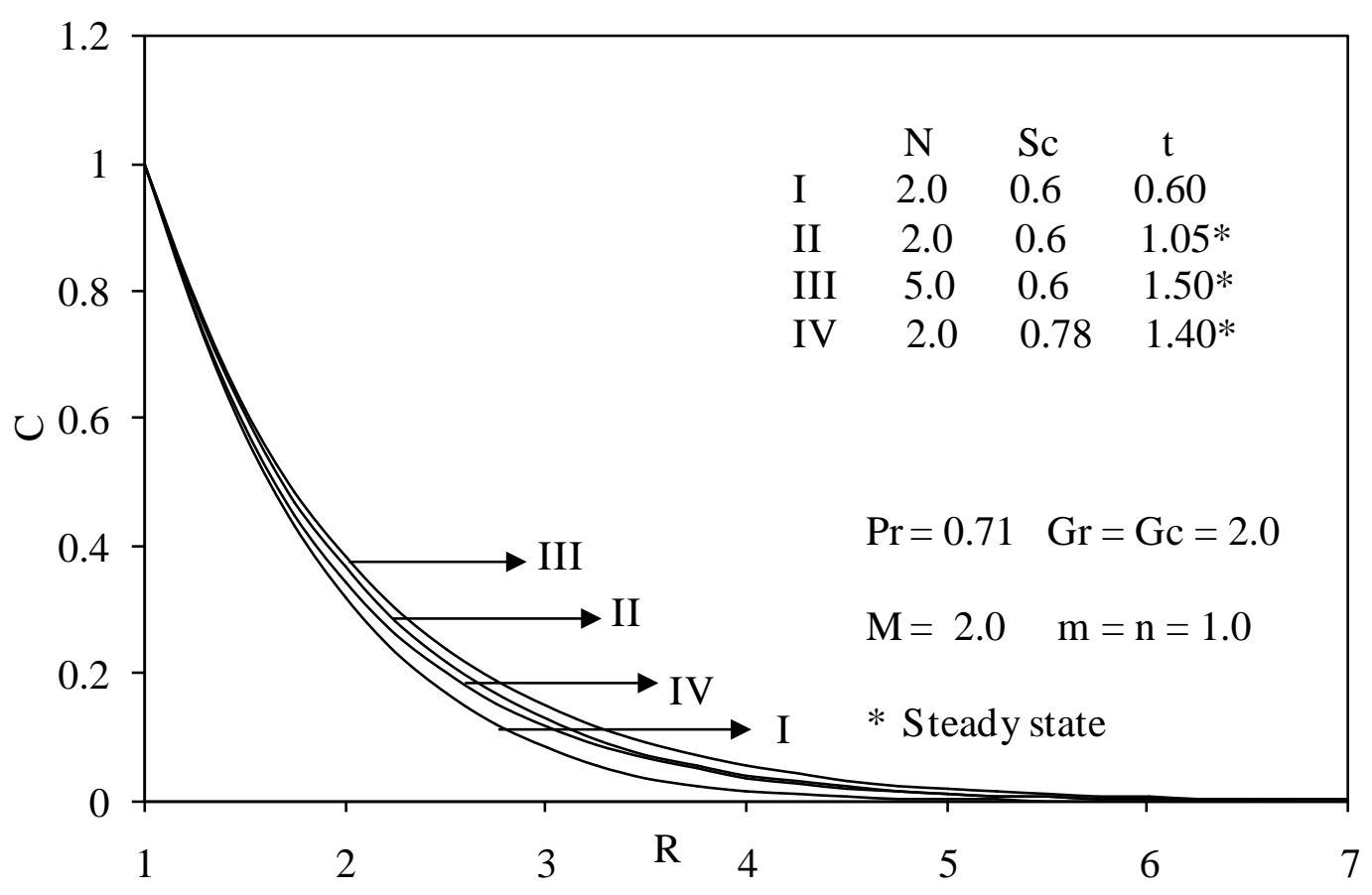

Fig.6. Transient concentration profiles at $\mathrm{X}=1.0$ for different $\mathrm{N}$ and Sc

It is seen that the concentration increases with an increase in ${ }_{N}$. As $S_{c}$ increases the mass transfer rate increases. Hence, the concentration decreases as $S c$ increases. The time required to reach the steady state concentration increases with an increase in $S_{c}$ or $N$.

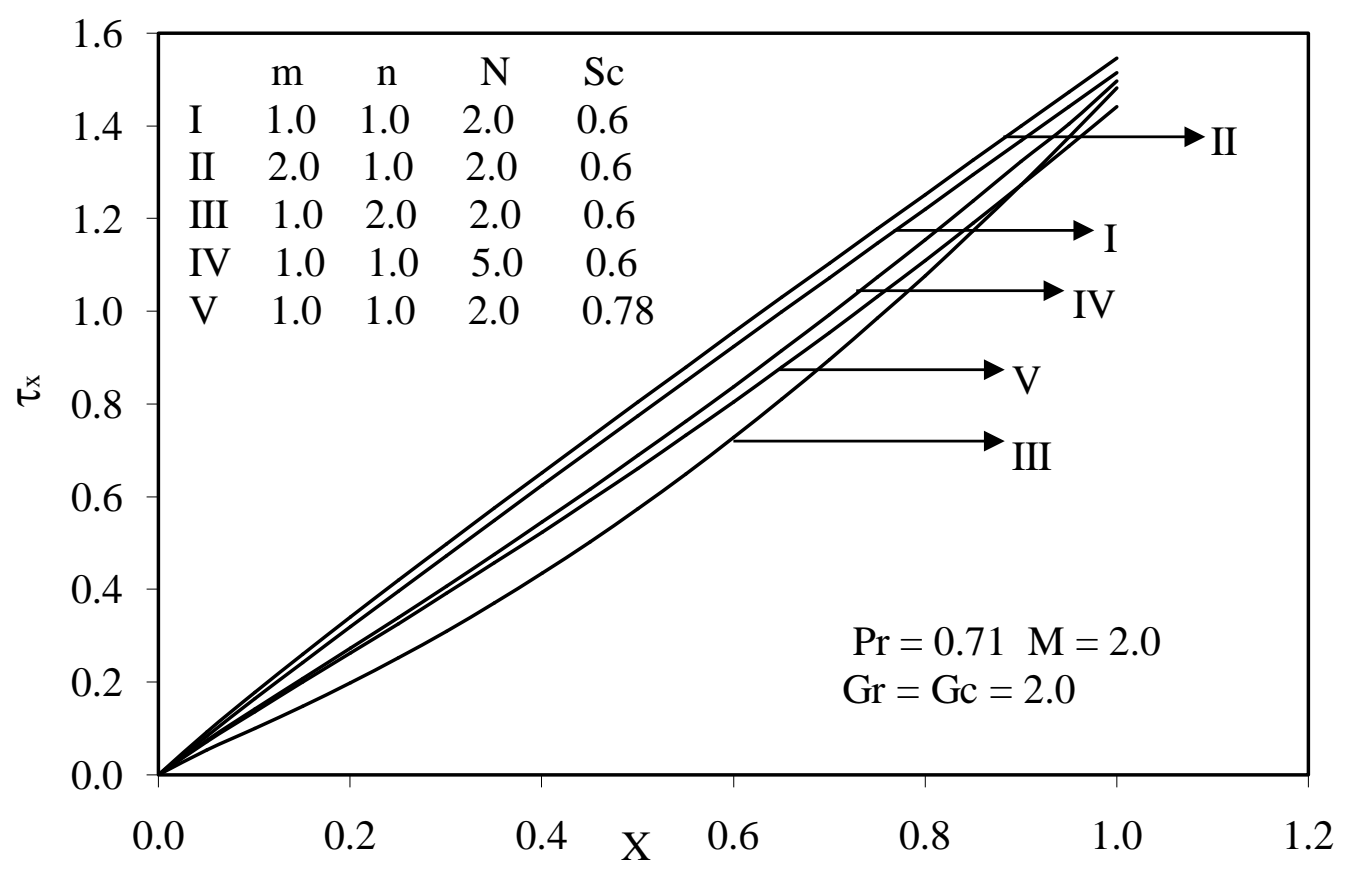

Fig.7. Local skin-friction. 
The effects of $m, n, N$ and $S c$ on the local skin-friction $\left(\tau_{x}\right)$ are shown in Fig.7. It is observed that, the local skin-friction decreases with an increase in ${ }_{n}$ or ${ }_{N}$ or $S c$, while it increases with an increase in $m$. Fig.8 displays the effects of $m, n, N$ and $S c$ on the average skin-friction $(\bar{\tau})$. The average skin-friction decreases with an increase in ${ }_{n}$ or $N$ or $S c$, while it increases with an increase in $m$.

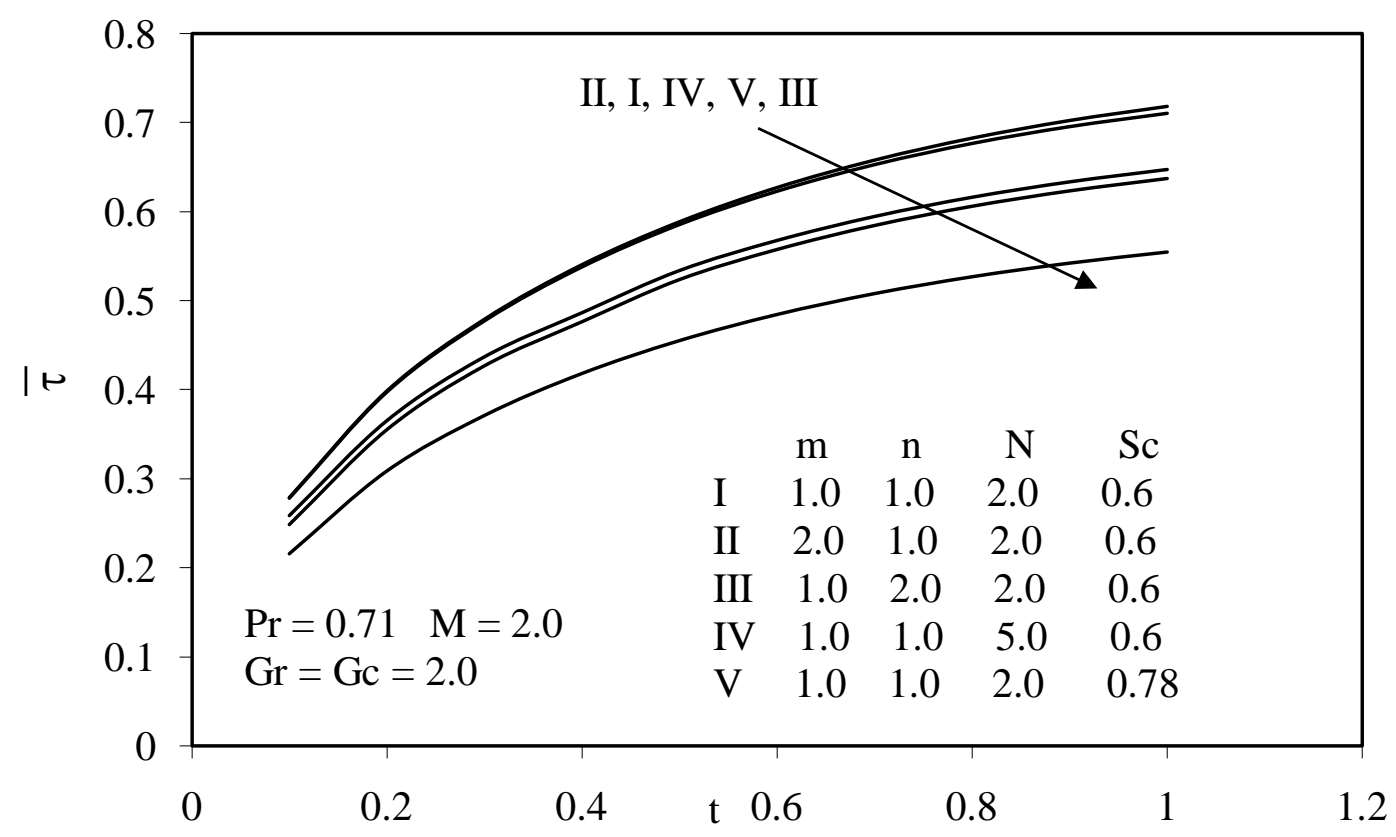

Fig.8. Average skin-friction

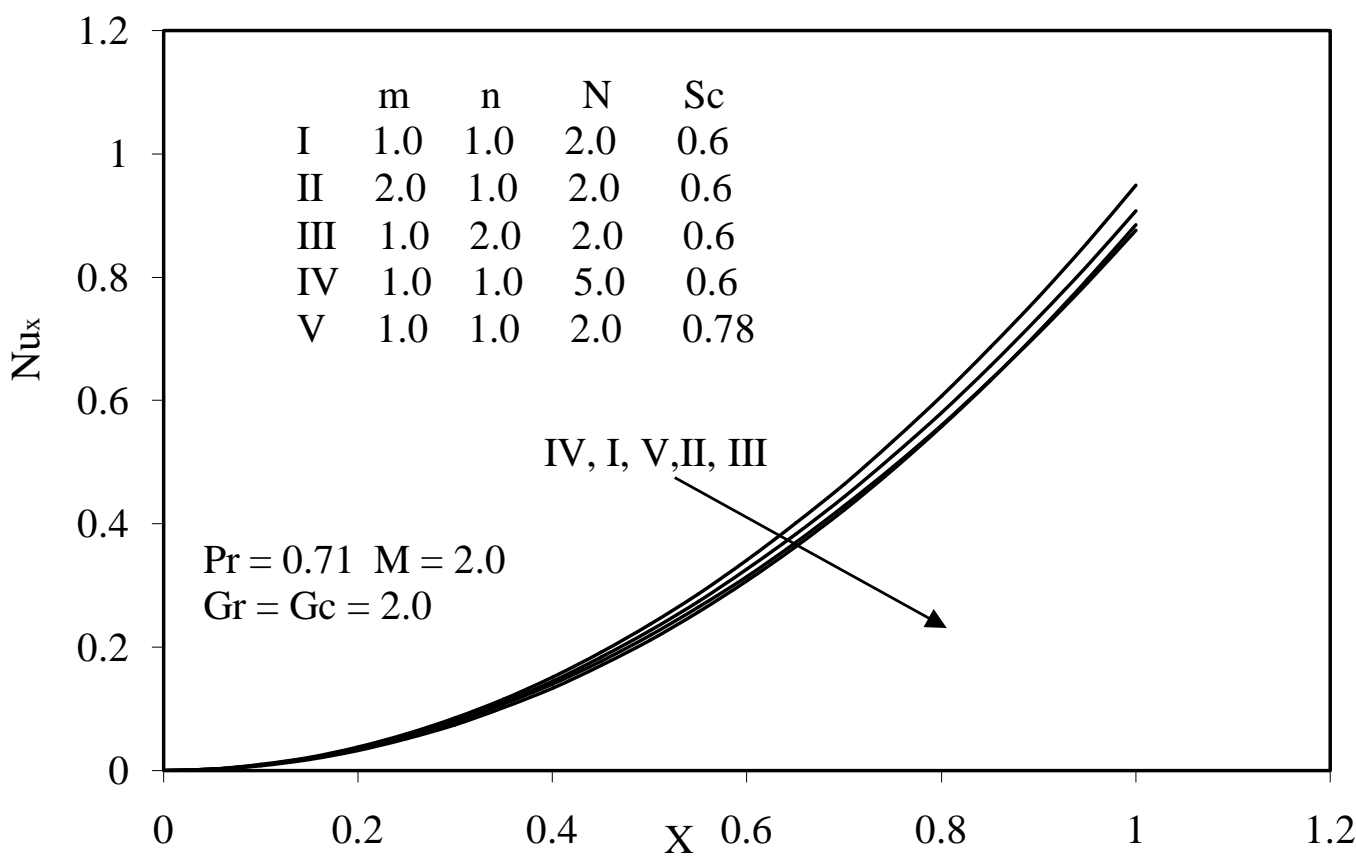

Fig.9. Local Nusselt number 
The local Nusselt number $\left(\mathrm{Nu}_{X}\right)$ for different values of $m, n, N$ and $S c$ are shown in Fig. 9. It is noticed that, the local Nusselt number decreases with an increase in $m$ or $n$ or $S c$, while it increases with an increase in $N$.

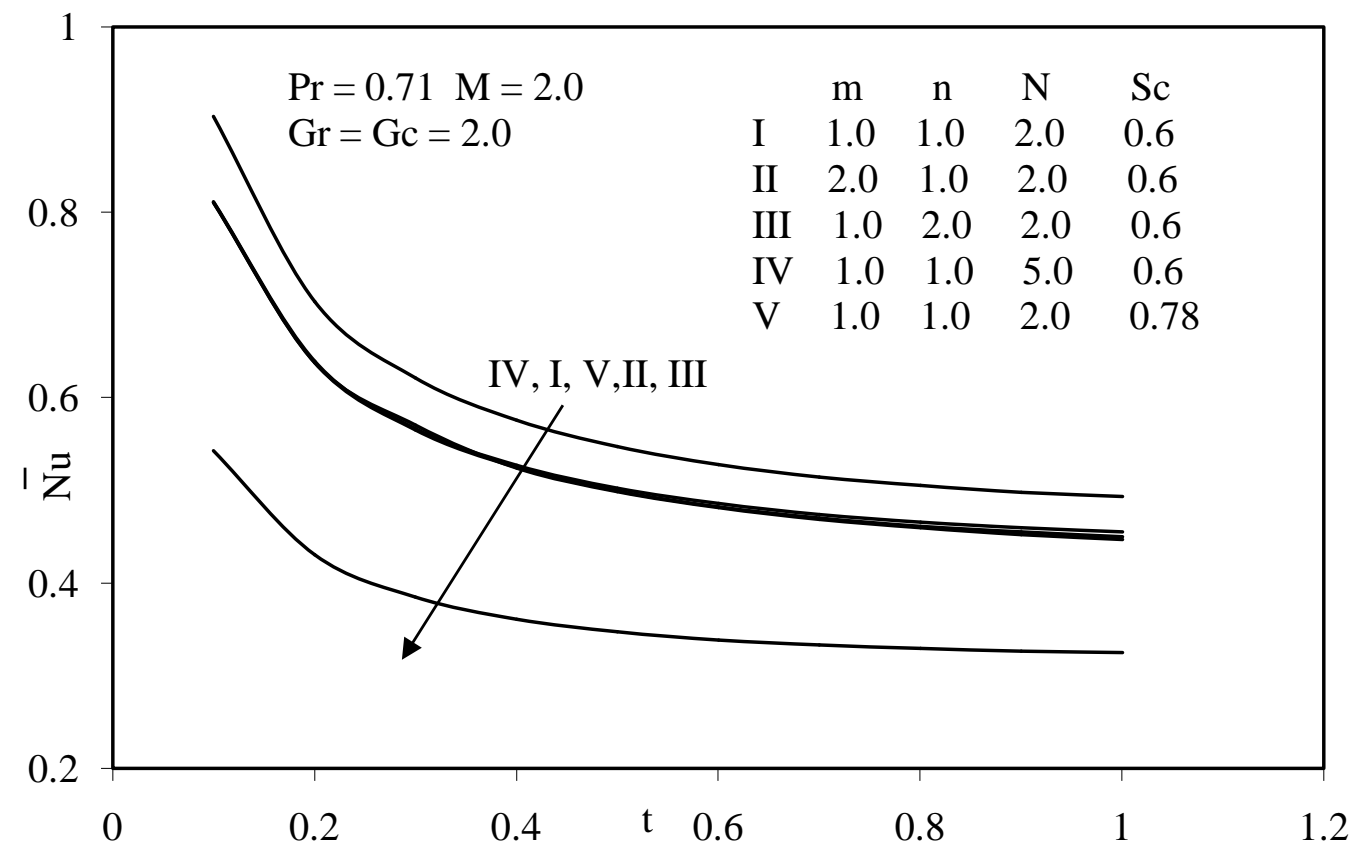

Fig.10. Average Nusselt number

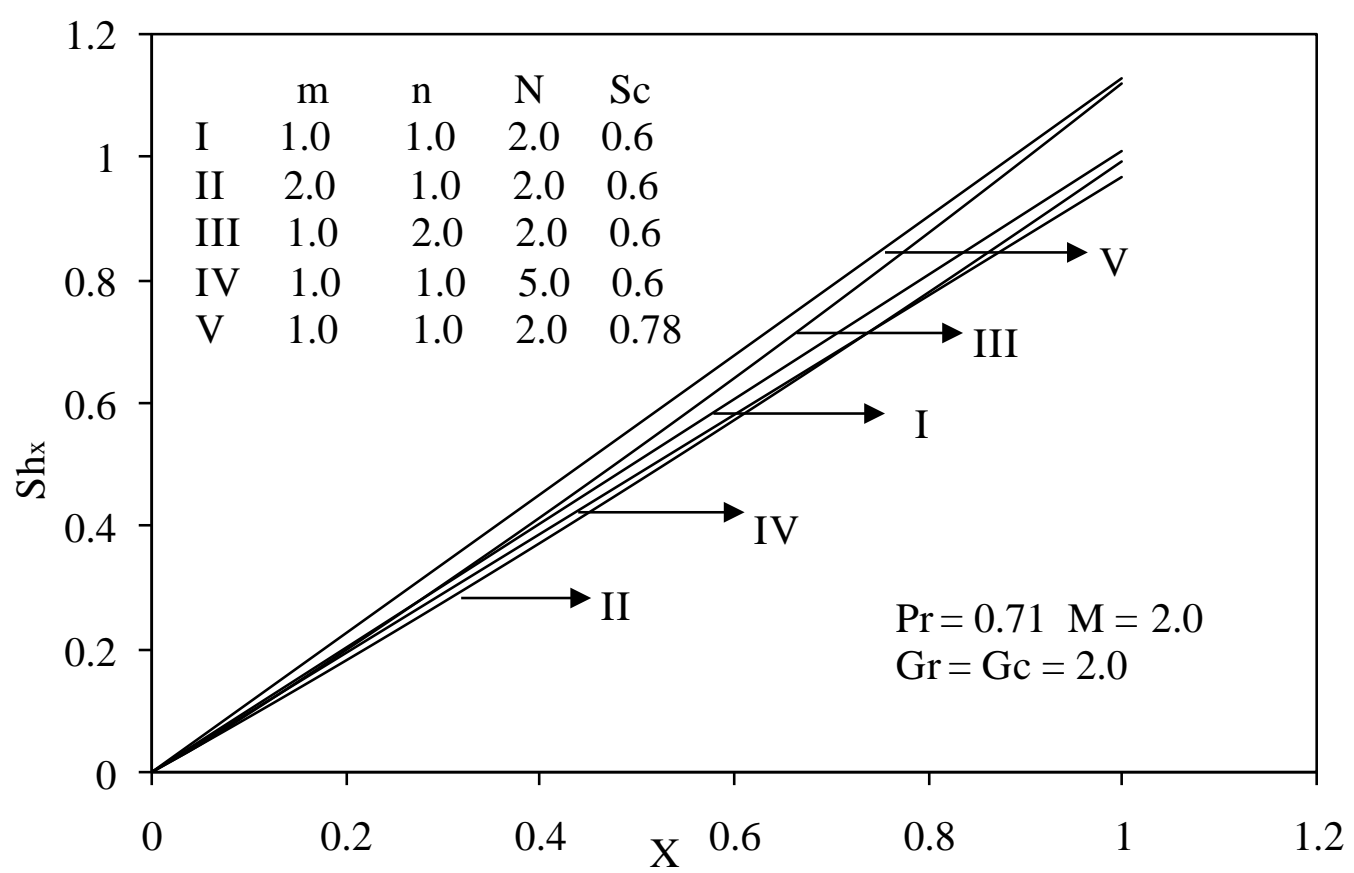

Fig.11. Local Sherwood number 
Fig.10 shows the effects of $m, n, N$ and $S c$ on the average Nusselt number $(\overline{N u})$. The average Nusselt number decreases with an increase in $m$ or $n$ or $S c$, while it increases with an increase in $N$. The effects of $m, n, N$ and $S c$ on the local and average Sherwood numbers are shown in Figs. 11 and 12 respectively. It is seen that both the local and average Sherwood numbers increase with an increase in ${ }_{n}$ or $S c$, while they decrease with an increase in $m$ or $N$.

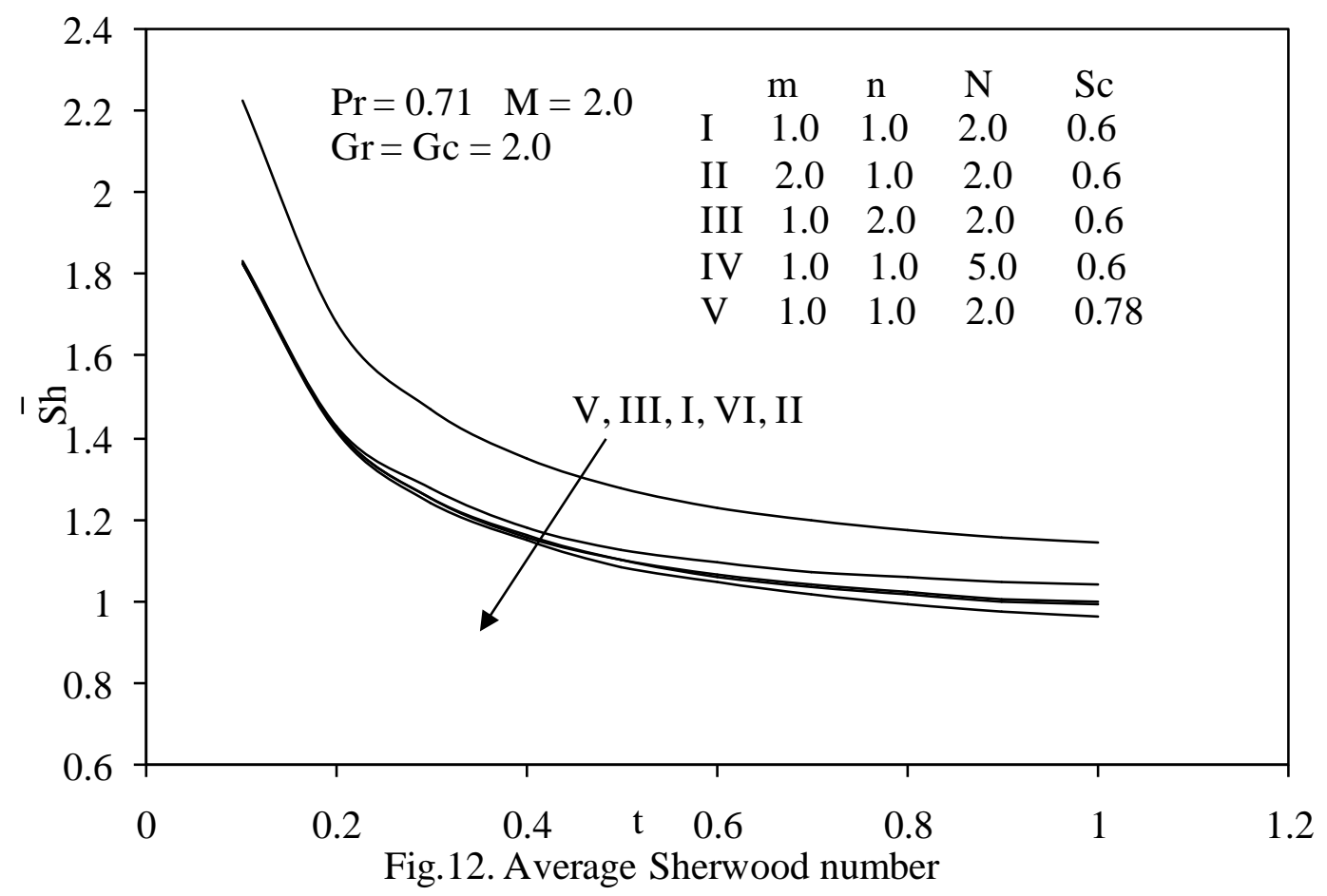

\section{Conclusions}

A numerical study has been carried out to study the interaction of free convection with thermal radiation of a viscous incompressible unsteady MHD flow past a vertical cylinder with variable surface temperature and concentration The fluid is gray, absorbing-emitting but non-scattering medium and the Rosseland approximation is used to describe the radiative heat flux in the energy equation. A family of governing partial differential equations is solved by an implicit finite difference scheme of Crank-Nicolson type, which is stable and convergent. The conclusions of this study are as follows:

1. The transient velocity increases with an increase in ${ }_{G r}$ or ${ }_{G c}$.

2. As the magnetic field parameter ${ }_{M}$ increases, the transient velocity.

3 . The time required for velocity to reach the steady-state increases as radiation parameter, ${ }_{N}$ increases.

4. The concentration reduces with an increase in ${ }_{m}$ or ${ }_{n}$ or $S c$.

5. The skin-friction decreases with an increase ${ }_{M}$ and increases with the increasing 


\section{References}

Sparrow E.M. and Gregg J.L. (1956): Laminar free convection heat transfer from the outer surface of a vertical circular cylinder, Trans. ASME, Vol.78, pp.1823-1830.

Lee H.R., Chen T.S. and Armaly B.F. (1988): Natural convection along slender vertical cylinders with variable surface temperature, J. Heat transfer, Vol.100, pp.103-108. doi:10.1115/1.3250439

Velusamy K. and Garg V.K.(1992): Transient natural convection over a heat generating vertical cylinder, Int. J. Heat Mass Transfer, Vol. 35, pp.1293-1306. doi:10.1016/0017-9310(92)90185-U

Bottemanne F.A. (1972): Experimental results of pure and simultaneous heat and mass transfer by free convection about a vertical cylinder for and, Appl. Sci. Res., Vol. 25, pp.372-381. doi:10.1007/BF00382310

Rani H.P. (2003): Transient natural convection along a vertical cylinder with variable surface temperature and mass diffusion, Heat Mass Transfer, Vol. 40, pp.67-73. doi:10.1007/s00231-002-0372-1

Chen T.S. and Yuh C.F. (1980): Combined heat and mass transfer in natural convection along a vertical cylinder, Int. J. Heat Mass transfer, Vol.23, pp.451-461. doi:10.1016/0017-9310(80)90087-3

Ganesan P. and Rani H.P. (1999): Unsteady free convection on a vertical cylinder with variable heat and mass flux, Heat Mass Transfer, Vol.35, pp.259-265. doi:10.1007/s002310050322

Ganesan P. and Rani H.P. (2003): Magnetic field effect on a moving vertical cylinder with constant heat flux, Heat Mass Transfer, Vol. 39, pp.381-386.

Elbashbeshy E.M.A. (1997): Heat and mass transfer along a vertical plate with variable surface temperature and concentration in the presence of magnetic field, Int. J. Eng. Sci., Vol.34, pp.515-522. doi:10.1016/S0020-7225(96)00089-4

Agarwal A.K., Kishor B. and Raptis A. (1989): Effect of MHD free convection and mass transfer on the flow past a vibrating infinite vertical circular cylinder, Heat Mass Transfer, Vol. 24, pp.243-250. Takhar H.S., Chamkha A.J. and Nath G. (2000): Combined heat and mass transfer along a vertical cylinder with free stream, Heat Mass Transfer, Vol.36, pp.237-246. doi:10.1007/s002310050391

Ganesan P. and Rani H.P. (1998): Transient natural convection cylinder with heat and mass transfer, Heat Mass Transfer, Vol.33, pp.449-455. doi:10.1007/s002310050214

Abd El-Naby M.A., Elsayed M.E., Elbarbary M.E. and Nader Y.A. (2003): Finite difference solution of radiation effects on MHD free convection flow over a vertical plate with variable surface temperature, J. Appl. Math., Vol.2, pp.65-86. doi:10.1155/S1110757X0320509X

Ramachandra Prasad V., Bhaskar Reddy N. and Muthucumaraswamy R. (2006): Finite difference analysis of radiation and mass transfer effect on MHD free convection flow past a vertical plate in the presence of heat source/sink, Int. J. Pure and Appl. Mathematics, Vol.2, No.2.

Yih K.A. (1999): Radiation effects on natural convection over a vertical cylinder embedded in porous media, Int. Comm. Heat Mass Transfer, Vol.26 (2), pp.259-267. doi:10.1016/S0735-1933(99)00012-3

Ganesan P. and Loganathan P. (2002): Radiation and mass transfer effects on flow of an incompressible viscous fluid past a moving vertical cylinder, Int. J. Heat Mass Transfer, Vol.45, pp.4281-4288. doi:10.1016/S0017$\underline{9310(02) 00140-0}$

Brewster M.Q. (1992): Thermal radiative transfer and properties, John Wiley \& Sons, NewYork. Carnahan B., Luther H.A. and Wilkes J.O. (1969): Applied Numerical Methods, John Wiley \& Sons, New York. Richtmyer Robert D. and Morton K.W. (1967): Difference methods for initial-Value Problems, John Wiley \& Sons, New York. 